\title{
A laboratory demand optimisation project in primary care
}

Magda Bucholc ${ }^{1}$, Maurice O'Kane ${ }^{2}$, Brendan O'Hare ${ }^{3}$, Ciaran Mullan ${ }^{3}$, Paul Cavanagh $^{3}$, Siobhan Ashe ${ }^{2}$, KongFatt Wong-Lin ${ }^{1}$

${ }^{1}$ Intelligent Systems Research Centre, University of Ulster, Magee Campus, Londonderry BT48 7JL, Northern Ireland, UK

${ }^{2}$ Altnagelvin Area Hospital, Western Health and Social Care Trust, Glenshane Road, Londonderry BT47 6SB, Northern Ireland, UK

${ }^{3}$ Western Local Commissioning Group, Gransha Park House, Clooney Road, Londonderry BT 47 6FN, Northern Ireland, UK

Correspondence to

Dr Magda Bucholc

Email: bucholc-m@email.ulster.ac.uk 


\section{Abstract}

2 Background: There is evidence of increasing use of laboratory tests with

3 substantial variation between clinical teams which is difficult to justify on clinical

4 grounds. The aim of this project was to assess the effect of a demand

5 optimisation intervention on laboratory test requesting in primary care.

6 Methods: The intervention comprised educational initiatives, feedback to 55

7 individual practices on test request rates with ranking relative to other practices,

8 and a small financial incentive for practices to engage and reflect on their test

9 requesting activity. Data on test request numbers were collected from the

10 laboratory databases for consecutive 12 month periods; pre-intervention 2011-

11 12, intervention 2012-13, 2013-14, 2014-15, and post-intervention 2015-16.

12 Results: The intervention was associated with a $3.6 \%$ reduction in the mean

13 number of profile test requests between baseline and 2015-16, although this

14 was seen only in rural practices. In both rural and urban practices, there was a

15 significant reduction in-between practice variability in request rates. The mean

16 number of $\mathrm{HbA}_{1 \mathrm{c}}$ requests increased from 1.9 to 3.0 per practice patient with

17 diabetes. Variability in $\mathrm{HbA}_{1 \mathrm{c}}$ request rates increased from $23.8 \%$ to $36.6 \%$. At

18 all considered time points, test request rates and variability were higher in rural

19 than in urban areas.

20 Conclusions: The intervention was associated with a reduction in both the

21 volume and between practice variability of profile test requests, with differences

22 noted between rural and urban practices. The increase in $\mathrm{HbA}_{1 \mathrm{c}}$ requests may 
23 reflect a more appropriate rate of diabetes monitoring and also the adoption of

$24 \quad \mathrm{HbA}_{1 \mathrm{c}}$ as a diagnostic test.

26 Keywords: laboratory test; test request variability; clinical intervention; clinical

27 pathology; primary care

29 Strengths \& limitations of the study

- We assessed the effect of a laboratory demand optimisation intervention both on the value and between GP practice variability in laboratory test requesting.

- The changes in laboratory test requesting were separately evaluated for rural and urban GP practices.

- Other factors (GP practice organisation, characteristics of general practitioners) potentially affecting between practice differences in laboratory test ordering were not taken into account due to data unavailability.

- The demand management initiative was not accompanied by the costeffectiveness analysis.

- The demand optimisation intervention was conducted in a Northern Ireland (NI) Western Health and Social Care Trust and the findings have not been independently replicated in any other NI trusts. 


\section{Introduction}

46 Despite the important role of laboratory testing in the diagnosis and monitoring

47 of disease, there is concern about the increasing use of laboratory tests and in

48 particular, the substantial variation in test ordering rates between clinical teams

49 [1]. In the UK laboratory test requests increased by approximately $5 \%$ per year

50 in the period 2012-15 [2]. While it is difficult to specify for most tests what an

51 'appropriate' test request rate might be for a given patient population, it is

52 probable that variability in test ordering rates reflects both inappropriate over-

53 and under-requesting [3,4]. Several studies have suggested that around 25-

$5440 \%$ of test requests may be unnecessary [5,6], and do not contribute to patient

55 management. This may reflect a lack of knowledge about the appropriate use of

56 individual tests, the use of different clinical guidelines and protocols, inability to

57 access previous results or defensive behaviour of physicians due to fear of

58 errors and medical malpractice litigation [7-10]. Unnecessary testing is not only

59 wasteful of resources but impacts on patients directly through the requirement

60 for venepuncture and the follow up of minor (and possibly insignificant)

61 abnormalities detected and which may cause patient anxiety. Inappropriate

62 under requesting may cause harm through failure to diagnose or manage

63 disease optimally.

64 Various demand optimisation interventions have been proposed to encourage

65 more appropriate laboratory testing and include educational initiatives on the

66 role and limitations of individual tests and appropriate retest intervals [11-14],

67 [15], feedback on test usage [16-19], redesigning of laboratory tests request 
68 forms [20], the introduction of locally agreed clinical guidelines [21,22] and

69 prompts on electronic test ordering systems. The effectiveness of such

70 interventions is variable and depends in part on local factors and local clinical

71 team engagement. Furthermore, such interventions may be time consuming

72 and expensive; a study on educational interventions conducted in hospital

73 settings showed that the savings on the direct hospital costs resulting from

74 interventions were smaller than the cost of interventions [23].

75 The aim of this study was to investigate the effect of a laboratory demand 76 optimisation intervention in a primary care setting on both laboratory test

77 request rates and on the variability between practices in test request rates.

\section{Materials and methods}

79 This study was undertaken in 55 separate primary care medical practices within

80 the catchment area of the Western Health and Social Care Trust (WHSCT).

81 The WHSCT provides laboratory services to these practices with networked

82 laboratories in each of the three large urban centres of Londonderry, Omagh,

83 and Enniskillen. The patient population served by the 55 practices over the 5-

84 year study period was 316382 (2011-12), 316688 (2012-13), 318057 (2013-

85 14), 319383 (2014-2015), and 326429 (2015-2016).

86 The primary care practices were situated in both rural and urban areas using

87 data from the Census Office of the Northern Ireland Statistics and Research

88 Agency [24]. Since the Northern Ireland settlement classification does not give continuous spans of particular area types, a practice was designated as urban if 
90 its postal address was situated in a settlement of more than 10,000 residents

91 following the urban-rural classification thresholds used by the Department for

92 Environment, Food and Rural Affairs (DEFRA) and the Department for

93 Communities and Local Government (DCLG) [24]. Under this definition, 31

94 practices were designated as urban and 24 as rural.

95 Data on laboratory test requests from individual primary medical practices were 96 studied over five consecutive 12 month periods (1 April to 31 March) from 2011-

9712 (the pre-intervention or 'baseline' period) to $2015-16$. Test request data were

98 extracted from the laboratory databases of the Altnagelvin Area Hospital,

99 Tyrone County Hospital, and the Erne Hospital (subsequently the South West

100 Acute Hospital). Information on individual primary care practices regarding

101 registered patient numbers, the number of male patients, and patients with

102 diabetes was obtained from the Western Health and Social Services Board

103 Integrated Care Partnership.

104 The following test groups were studied: electrolyte profile, lipid profile, thyroid 105 profile (FT4 and TSH), liver profile, immunoglobulin profile, glycosylated 106 haemoglobin $\left(\mathrm{HbA}_{1 \mathrm{c}}\right)$, and prostate-specific antigen (PSA). The number of 107 profile tests (electrolyte profile, lipid profile, thyroid profile, liver profile,

108 immunoglobulin profile) requested in each practice was standardised against

109 the number of registered patients in the practice and expressed as requests per

1101000 patients. $\mathrm{HbA}_{1 \mathrm{c}}$ was standardised against the number of patients with

111 diabetes per practice while PSA was standardised against the number of male 112 patients per practice. 
113 Throughout the study period laboratory requests from primary care were

114 ordered on a paper laboratory request form. All of the test considered here (with

115 the exception of immunoglobulins) were listed on the request form and could be

116 ordered by ticking a box on the test request form adjacent to the test profile

117 name; an immunoglobulin profile was ordered by free text entry on the request

118 form.

119 Test requesting rates were studied before and after a three year intervention

120 designed to support optimal use of laboratory testing. The intervention package

121 was developed in conjunction with the Western Local Commissioning Group

122 (responsible for commissioning and managing primary care services and which

123 included senior primary care doctors). The intervention included several

124 discrete elements. Firstly, awareness of the intervention was promoted through

125 educational sessions on the benefits to patients and clinical teams of optimal

126 use of laboratory tests. Secondly, educational material was developed in

127 conjunction with primary care clinicians which covered the major clinical

128 indications for a range of considered requested tests and appropriate retest

129 intervals. This was distributed to all primary care teams and was supplemented

130 by presentations at educational meetings. Thirdly, all primary care teams were

131 asked to engage in the process of reviewing test requesting procedures within

132 their practice, and to reflect on the information provided on their practice test

133 requesting rates and ranking in comparison to other practices. The active

134 intervention took place over the three year period: $2012-13,2013-14$, and 2014-

13515. 
136 Prior to the intervention each practice received information on its standardised

137 test request rates (see below) over the previous year (baseline period) and its

138 ranking in relation to standardised test request rates of all other practices

139 served by the laboratory.

140 The Western Local Commissioning Group (WLCG) made available funding to

141 incentivise participation in this process. All participating primary care practices

142 received a payment of $£ 0.30$ per patient registered on their practice list to

143 engage in the process or reviewing and reflecting on test requesting activity.

144 Changes in the absolute numbers of standardised test requests and between-

145 practice variability in standardised test request rates were compared to the pre-

146 intervention ('baseline') period (April 2011 - March 2012).

147 Variability between practices in standardised test request rates was expressed

148 as coefficient of variation (CV) whereas differences in the variance between

149 pre- and post-intervention period were tested using the Bonett-Seier test [25].

150 A paired t-test was used to compare mean numbers of laboratory test requests

151 from pre- and post-intervention period.

152 Spearman's rank correlation was used to study relationships between

153 standardised requesting rates for three of the most commonly request tests

154 (electrolyte, liver, and lipid tests) within individual practices [26]. All statistical

155 analyses were performed using $R$ statistical software, version 3.3.3 ( $R$

156 Foundation for Statistical Computing, Vienna, Austria). 


\section{Results}

159 The total number of profile test requests for all practices fell from a mean of 1601554 per 1000 patients pre-intervention to 1498 per 1000 patients one year 161 post intervention (a reduction of $3.7 \% ; p=0.09$ ) (Table 1). Rural practices had

162 a higher average standardised profile request rate than urban practices at all

163 time points: baseline, during the intervention and at one year post intervention.

164 However, the reduction in the mean number of test requests was seen 165 exclusively in rural practices where requests fell by $9 \%(p=0.01)$ as compared 166 with no significant change in urban practices.

167 The between practice coefficient of variation for profile test requests fell from

$16830.2 \%$ pre-intervention to $27.4 \%$ one year post intervention $(p=0.049)$. Rural

169 practices had a higher between practice coefficient of variation than urban

170 practices at all time points (Table 1). There was no significant difference

171 between urban and rural practices in the number of registered patients per 172 general practitioner.

173 For $\mathrm{HbA}_{1 \mathrm{c}}$, there was an increase in mean test request rates from 1.9 requests

174 per patient with diabetes pre-intervention to 3.0 diabetes post-intervention ( $p$

$175=0.00001)($ Table 2$)$. Variability for $\mathrm{HbA}_{1 \mathrm{c}}$ increased from $23.8 \%$ to $36.6 \%(p=$ 176 0.00001). The statistically significant increase in variation for $\mathrm{HbA}_{1 \mathrm{c}}$ was 177 observed both in rural $(p=0.00031)$ and urban $(p=0.008)$ areas (Table 2$)$. 
178 The mean number of PSA requests per 1000 male patients increased from 69.4

179 to 82.9 following the intervention $(p=0.006)$ (Table 3). However, there was no

180 significant change in between practice variability.

181 Finally, there were high correlations within practices for individual profile test

182 types: electrolyte and liver profiles $(R=0.83)$, and lipids and liver profiles $183(\mathrm{R}=0.67)$ (Figure 1).

\section{Discussion}

185 While it may be challenging to define what represents an appropriate rate of

186 requesting for most tests, it is certainly difficult to justify very high levels of

187 variability between clinical teams providing care to broadly similar groups of 188 patients within a single healthcare system. This study found high levels of

189 baseline variability between primary care practices in standardised biochemistry

190 profile test request rates both in rural (32.1\%) and urban areas $(24.7 \%)$. There

191 is little reason to believe that there were significant differences in the

192 characteristics of the practice patient populations within each of rural and urban

193 areas in terms of disease prevalence or morbidity that might explain such high

194 variability. It is therefore likely that the variability observed reflects differing

195 behaviours and perceptions between clinical teams as to the value and role of

196 individual tests in patient assessment.

197 The baseline standardised profile test request rates were significantly higher in

198 rural than in urban practices. The reasons for this are unclear and were beyond

199 the scope of investigation of the present study. However possible explanations 
200 include differences in practice organisation and workflow, differences in the

201 characteristics of general practitioners such as training, background, age which

202 might lead to differences in approach to patient assessment and testing $[27,28]$.

203 The intervention employed to optimise demand was associated with two effects.

204 Firstly, there was a reduction of $3.7 \%$ in total standardised profile test requests

205 (as measured at one year post intervention). However, this was accounted for 206 entirely by a reduction in rural practices. Secondly, there was also a significant

207 reduction in between practice variability in test requesting from $30.2 \%$ to $27.4 \%$

208 and this was seen in both urban and rural practices. During and post-

209 intervention, the standardised test request rates and variability continued to be

210 higher in rural than urban practices.

211 For $\mathrm{HbA}_{1 \mathrm{c}}$ the standardised test rate per patient with diabetes increased from

2121.9 to 3 tests per patient with diabetes per year. Best practice guidelines

213 suggest measuring $\mathrm{HbA}_{1 \mathrm{c}}$ two to three times per year in patients with diabetes

214 and this had been highlighted in the educational material that formed part of the

215 intervention [29]. The increased testing rate may therefore reflect more

216 appropriate monitoring of patients with diabetes. However, as it was not

217 possible to distinguish $\mathrm{HbA}_{1 \mathrm{c}}$ samples which had been requested for diabetes

218 monitoring from those requested for the purposes of diabetes diagnosis, it is

219 difficult to be certain. The use of $\mathrm{HbA}_{1 \mathrm{c}}$ as a diagnostic test for diabetes mellitus

220 had been introduced in 2012 i.e. during the baseline period and it is possible

221 that the increase in requesting (and the observed increase in between practice 
222 variability) reflected its adoption as a diagnostic test rather than as a monitoring

223 test.

224 Within individual practices, there was high correlation between standardised

225 request rates for different test profiles. The reasons for such correlations are

226 unclear. In some instances, there may be good reasons why different test

227 profiles should be requested together e.g. monitoring liver enzymes along with

228 lipids for patients on statin therapy. In other cases, there may be patients with

229 complex medical conditions and a number of co-morbidities in whom it is

230 appropriate to request a number of test profiles simultaneously. A further

231 possibility is that the co-requesting of different test profiles reflects a 'scatter

232 gun' approach to test requesting. This may also have inadvertently been

233 facilitated by the design of the test request form on which tests are requested

234 simply by ticking a box beside the relevant test profile.

235 Previous studies on demand optimisation in primary care have yielded varying

236 results with some studies showing reductions of up to $12 \%[17,19,30-32]$

237 following a range of educational and feedback interventions or guideline driven

238 decision support systems. Studies which targeted the utilization of specific

239 laboratory tests also showed that the interventions generally produced changes

240 in the desired direction. For example, educational initiatives were found to

241 improve significantly the management of albuminuria [33], oral anticoagulation

242 [34], C-reactive protein [35], $\mathrm{HbA}_{1 \mathrm{c}}$ [36-38], lipids [36-39], and Pap testing [40].

243 The improvement was more likely to be observed when more than one type of

244 intervention was used at a time $[38,41]$. 
245 Although numerous previous studies had documented high degrees of

246 variability in test requesting between primary care teams [32,42,43], a unique

247 feature of the present study was that it assessed the effect of the intervention

248 on between practice variability in test requesting. The reduction in variability

249 found here suggests that the intervention was associated with a more

250 standardised approach to patient investigation and monitoring.

\section{Conclusions}

252 In conclusion, the demand optimisation intervention undertaken here showed a

253 small but significant reduction in reducing unwarranted variability between

254 practices in test requesting rates.

257 Data

258 The information on datasets supporting this article have been provided in the

259 supplementary material.

\section{Competing interests}

261 We have no competing interests

\section{Authors' contributions}

263 Contributors: MB performed the analysis and interpretation of the results, and

264 wrote the manuscript. She is guarantor. $\mathrm{MJO}, \mathrm{BOH}, \mathrm{CM}$ and $\mathrm{PC}$ designed and

265 carried out the demand management intervention. MJO wrote the manuscript. 
$266 \mathrm{BOH}, \mathrm{CM}$ and $\mathrm{PC}$ edited the manuscript. SA monitored the data collection and

267 edited the manuscript. KWL initiated the collaborative project, guided the data

268 analysis and interpretation of the results, and wrote the manuscript.

\section{Funding}

270 This work was performed under the Northern Ireland International Health

271 Analytics Centre (IHAC) collaborative network project funded by Invest NI

272 through Northern Ireland Science Park (Catalyst Inc). The funder had no role in

273 study design, data collection and analysis, decision to publish, or preparation of

274 the manuscript.

275 Acknowledgments

276 The authors would wish to thank the IHAC collaborative network, especially

277 Colm Hayden, Brendan Bunting and Le Roy Dowey for helpful discussions;

278 Graham Moore, Austin Tanney, and Paul Barber for computing and technical

279 support; and Stephen Lusty and Peter Devine for administrative support. 


\section{References}

1. Smellie WSA. Demand management and test request rationalization. Ann Clin Biochem 2012; 49(4): 323-36.

2. Karakusevic S, Edwards N, Lewis R, et al. The future of pathology services. 2016. Available from:

http://www.nuffieldtrust.org.uk/publications/futurepathology-services (accessed 20 Nov 2016).

3. Cadogan SL, Browne JP, Bradley CP, et al. The effectiveness of interventions to improve laboratory requesting patterns among primary care physicians: a systematic review. Implement Sci 2015;10(1):167.

4. Newman-Toker DE, McDonald KM, Meltzer DO, et al. How much diagnostic safety can we afford, and how should we decide? A health economics perspective. BMJ Qual Saf 2013;22: ii11-ii20.

5. Department of Health. Report of the review of NHS pathology services in England: an independent review for the Department of Health. 2006. Available from:

http://collection.europarchive.org/tna/20070706124823/http:/dh.gov.uk/en/P ublicationsandstatistics/Publications/PublicationsPolicyAndGuidance/DH 4 137606 (accessed 14 Nov 2016).

6. Furness P. Roundtable pathology. Health Service Journal Pathology 2011; $3: 3$ 
7. Weydert JA, Nobbs ND, Feld R, et al. A simple, focused, computerized query to detect overutilization of laboratory tests. Arch Pathol Lab Med 2005;129(9):1141-1143.

8. Wong ET, McCarron MM, Shaw ST. Ordering of laboratory tests in a teaching hospital: can it be improved? JAMA 1983;249(22):3076-3080.

9. Young DW. Improving laboratory usage: a review. Postgrad Med $J$ 1988;64(750):283-289.

10. Epstein AM, McNeil BJ. Relationship of beliefs and behavior in test ordering. Am J Med 1986; 80:865-870.

11. van der Weijden TR, Grol RP, Knottnerus JA. Feasibility of a national cholesterol guideline in daily practice. A randomized controlled trial in 20 general practices. Int J Qual Health Care 1999;11(2):131-137.

12. Thakkar RN, Kim D, Knight AM, et al. Impact of an educational intervention on the frequency of daily blood test orders for hospitalized patients. Am J Clin Pathol 2015;143(3):393-397.

13. Solomon $\mathrm{DH}$, Hashimoto $\mathrm{H}$, Daltroy $\mathrm{L}$, et al. Techniques to improve physicians' use of diagnostic tests: a new conceptual framework. JAMA 1998;280(23):2020-2027.

14. Borgiel AE, Williams JI, Davis DA, et al. Evaluating the effectiveness of 2 educational interventions in family practice. CMAJ 1999;161(8):965-970.

15. ESMO minimum clinical recommendations for diagnosis, treatment and follow-up of advanced colorectal cancer. Ann Oncol 2001;12:1055. 
16. Bugter-Maessen AM, Winkens RA, Grol RP, et al. Factors predicting differences among general practitioners in test ordering behaviour and in the response to feedback on test requests. Fam Pract 1996;13: 254-258.

17. Baker R, Falconer Smith J, Lambert PC. Randomised controlled trial of the effectiveness of feedback in improving test ordering in general practice. Scand J Prim Health Care 2003;21(4):219-223.

18. Buntinx F, Knottnerus JA, Crebolder HF, et al. Reactions of doctors to various forms of feedback designed to improve the sampling quality of cervical smears. Qual Assur Health Care 1992;4(2):161-166.

19. Bunting PS, Van Walraven C. Effect of a controlled feedback intervention on laboratory test ordering by community physicians. Clin Chem $2004 ; 50(2): 321-326$.

20. Showstack JA, Schroeder SA, Matsumoto MF. Changes in the use of medical technologies, 1972-1977: a study of 10 inpatient diagnoses. $N$ Engl J Med 1982; 306: 706-712.

21. Alonso-Cerezo MC, Martín JS, García Montes MA, et al. Appropriate utilization of clinical laboratory tests. Clin Chem Lab Med 2009;47(12):1461-1465.

22. Driskell OJ, Holland D, Hanna FW, et al. Inappropriate requesting of glycated hemoglobin ( $\mathrm{HbA} 1 \mathrm{c})$ is widespread: assessment of prevalence, impact of national guidance, and practice-to-practice variability. Clin Chem 2012;58(5):906-915. 
23. Schroeder SA, Myers LP, McPhee SJ, et al. The failure of physician education as a cost containment strategy: report of a prospective controlled trial at a university hospital. JAMA 1984;252(2):225-230.

24. Northern Ireland Statistics and Research Agency. Review of the Statistical Classification and Delineation of Settlements. 2015. Available from: http://www.nisra.gov.uk/archive/geography/review-of-the-statisticalclassification-and-delineation-of-settlements-march-2015.pdf (accessed 26 Oct 2016).

25. Bonett DG, Seier E. Statistical inference for a ratio of dispersions using paired samples. J Educ Behav Stat 2003;28: 21-30.

26. Walters SJ. Quality of life outcomes in clinical trials and health-care evaluation: a practical guide to analysis and interpretation. John Wiley \& Sons 2009.

27. Salinas M, López-Garrigós M, Uris J, Leiva-Salinas C, Pilot Group of the Appropriate Utilization of Laboratory Tests (REDCONLAB) working group. A study of the differences in the request of glycated hemoglobin in primary care in Spain: A global, significant, and potentially dangerous underrequest. Clinical biochemistry. 2014 Aug 31;47(12):1104-7.

28. Boerma WG, Groenewegen PP, Van der Zee J. General practice in urban and rural Europe: the range of curative services. Soc Sci Med 1998;47(4):445-453.

29. National Collaborating Centre for Chronic Conditions. Type 2 Diabetes: National Clinical Guidelines for Management in Primary and Secondary Care [update]. Royal College of Physicians, 2008. 
30. van Wijk MA, van der Lei J, Mosseveld M, et al. Compliance of general practitioners with a guideline-based decision support system for ordering blood tests. Clin Chem 2002; 48: 55-60.

31. Verstappen WH, van der Weijden T, Sijbrandij J, et al. Effect of a practicebased strategy on test ordering performance of primary care physicians. JAMA 2003; 289: 2407-2411.

32. Hobbs FD, Delaney BC, Carson A, et al. A prospective controlled trial of computerized decision support for lipid management in primary care. Fam Pract 1996; 13: 133-137.

33. Holbrook A, Thabane L, Keshavjee K, et al. Individualized electronic decision support and reminders to improve diabetes care in the community: COMPETE II randomized trial. CMAJ 2009;181(1-2):37-44.

34. Claes N, Buntinx F, Vijgen J, et al. The Belgian improvement study on oral anticoagulation therapy: a randomized clinical trial. Eur Heart $J$ 2005; 26: 2159-2165.

35. Hutton HD, Drummond HS, Fryer AA. The rise and fall of C-reactive protein: managing demand within clinical biochemistry. Ann Clin Biochem 2009; 46: 155-158.

36. Eccles M, Grimshaw J, Steen N, et al. The design and analysis of a randomized controlled trial to evaluate computerized decision support in primary care: The COGENT study. Fam Pract 2000; 17: 180-186.

37. Eccles M, McColl E, Steen N, et al. Effect of computerised evidence based guidelines on management of asthma and angina in adults in primary care: cluster randomised controlled trial. BMJ 2002; 325. 
38. Hetlevik I, Holmen J, Kruger O, et al. Implementing clinical guidelines in the treatment of diabetes mellitus in general practice. Evaluation of effort, process, and patient outcome related to implementation of a computerbased decision support system. Int J Technol Assess Health Care 2000; 16: $210-227$.

39. Moher $M$, Yudkin $P$, Wright $L$, et al. Cluster randomised controlled trial to compare three methods of promoting secondary prevention of coronary heart disease in primary care. BMJ 2001; 322: 1338.

40. Winkens RA, Pop P, Bugter-Maessen AM, et al. Randomised controlled trial of routine individual feedback to improve rationality and reduce numbers of test requests. Lancet 1995; 345: 498-502.

41. Bindels R, Hasman A, Kester AD, et al. The efficacy of an automated feedback system for general practitioners. Inform Prim Care 2003; 11: 6974.

42. O'Kane MJ, Casey L, Lynch PM, et al. Clinical outcome indicators, disease prevalence and test request variability in primary care. Ann Clin Biochem 2011; 48(2): 155-158.

43. Smellie WSA, Galloway MJ, Chinn D. Is clinical practice variability the major reason for differences in pathology requesting patterns in general practice? J Clin Pathol 2002; 55: 312-314. 
Figure 1. Practice standardized requests for electrolyte profiles plotted against liver profiles (A), and lipid profiles plotted against liver profiles (B), with Spearman's rank correlation coefficients $(R)$.
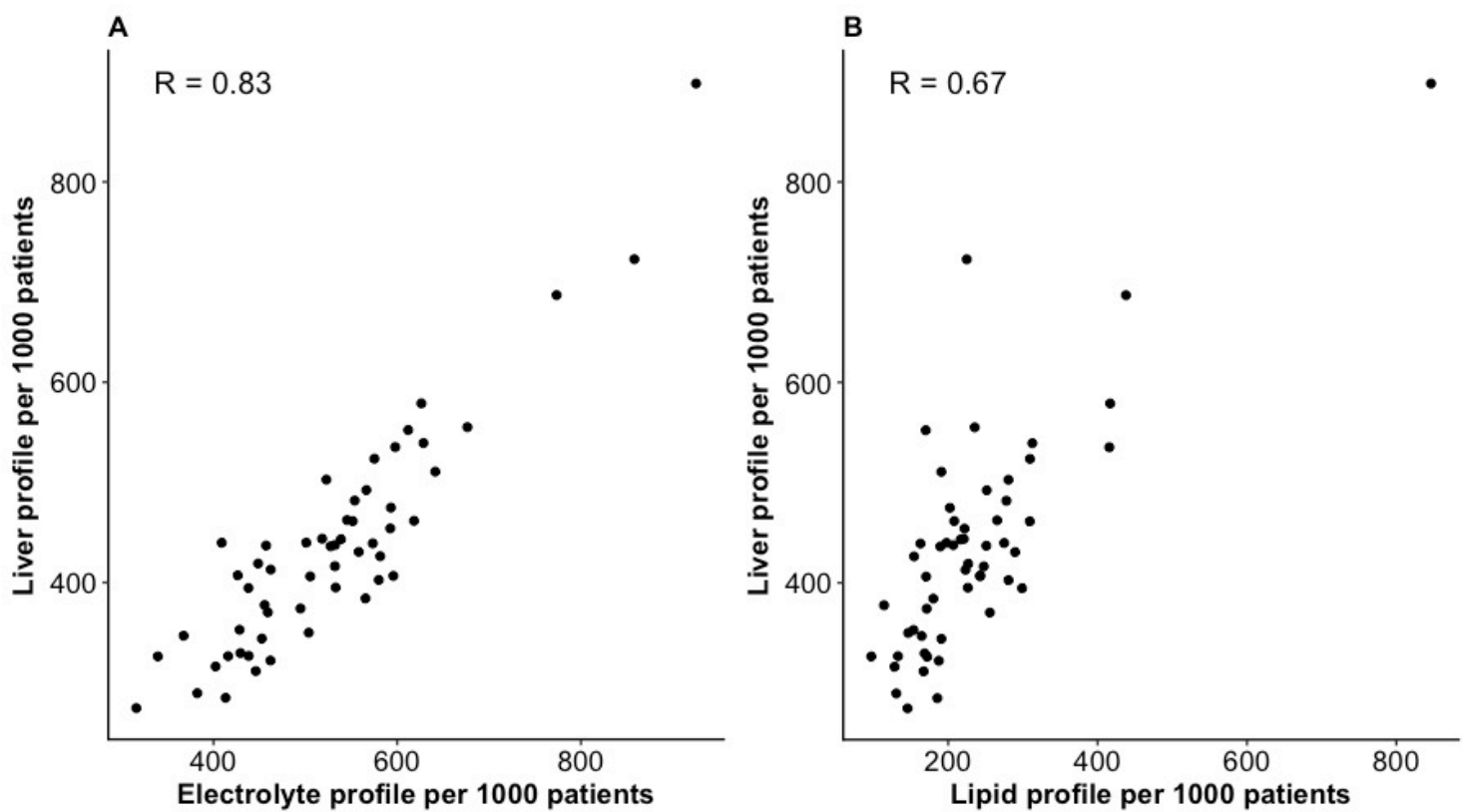
Table 1. Standardised profile test request rates per 1000 patients pre- and postintervention for all practices combined and for rural and urban practices. T-test pvalue refers to the significance level evaluating differences between the mean number of request rates in pre- and post-intervention period. The $\mathrm{p}$-value of BonettSeier test refers to the significance level assessing the difference in variances in preand post-intervention period. Asterisk: Statistically significant difference $(p<0.05)$ between the pre- and post-intervention data.

\begin{tabular}{|c|c|c|c|c|c|}
\hline & $\begin{array}{c}\text { Pre- } \\
\text { intervention }\end{array}$ & & Intervention & & $\begin{array}{c}\text { Post- } \\
\text { intervention }\end{array}$ \\
\hline Year & 2011-2012 & $2012-2013$ & 2013-2014 & $2014-2015$ & $2015-2016$ \\
\hline \multicolumn{6}{|l|}{$A I I$} \\
\hline Mean & 1554 & 1556 & 1499 & 1485 & 1498 \\
\hline (Range) & $(798-3919)$ & $(809-4043)$ & $(879-3918)$ & $(868-3840)$ & $(942-3530)$ \\
\hline Between practice CV (\%) & 30.2 & 30.1 & 29.5 & 29.4 & 27.4 \\
\hline$p$-value (t-test) & 0.09 & & & & \\
\hline$p$-value (Bonett-Seier test) & $0.049^{*}$ & & & & \\
\hline \multicolumn{6}{|l|}{ Rural } \\
\hline Mean & 1720 & 1726 & 1604 & 1581 & 1566 \\
\hline (Range) & $(998-3919)$ & $(1112-4043)$ & $(1139-3918)$ & $(868-3840)$ & $(1073-3530)$ \\
\hline Between practice CV (\%) & 32.1 & 32.0 & 34.5 & 34.6 & 31.4 \\
\hline$p$-value (t-test) & $0.01^{*}$ & & & & \\
\hline$p$-value (Bonett-Seier test) & 0.2 & & & & \\
\hline \multicolumn{6}{|l|}{ Urban } \\
\hline Mean & 1426 & 1424 & 1418 & 1410 & 1444 \\
\hline (Range) & $(798-2543)$ & $(809-2356)$ & $(879-2205)$ & $(893-2297)$ & $(942-2368)$ \\
\hline Between practice CV (\%) & 24.7 & 24.3 & 22.6 & 22.5 & 23.2 \\
\hline$p$-value (t-test) & 0.6 & & & & \\
\hline$p$-value (Bonett-Seier test) & 0.4 & & & & \\
\hline
\end{tabular}


Table 2. Standardised test request rates pre- and post-intervention for $\mathrm{HbA}_{1 \mathrm{c}}$ (expressed as number of tests per patient with diabetes). Asterisk: Statistically significant difference $(p<0.05)$ between the pre- and post-intervention data.

\begin{tabular}{|c|c|c|c|c|c|}
\hline \multicolumn{3}{|c|}{ Pre-intervention } & \multicolumn{2}{|l|}{ Intervention } & \multirow{2}{*}{$\begin{array}{c}\begin{array}{c}\text { Post- } \\
\text { intervention }\end{array} \\
2015-2016\end{array}$} \\
\hline Year & $2011-2012$ & $2012-2013$ & 2013-2014 & 2014-2015 & \\
\hline \multicolumn{6}{|l|}{$A I I$} \\
\hline Mean & 1.86 & 2.04 & 2.32 & 2.60 & 3.01 \\
\hline (Range) & $(1.07-3.07)$ & $(1.09-3.43)$ & $(1.33-4.59)$ & $(1.49-5.94)$ & $(1.71-8.06)$ \\
\hline Between practice CV (\%) & 23.8 & 26.2 & 33.2 & 34.9 & 36.6 \\
\hline$p$-value (t-test) & $<0.0000001^{*}$ & & & & \\
\hline$p$-value (Bonett-Seier test) & $0.00001^{*}$ & & & & \\
\hline \multicolumn{6}{|l|}{ Rural } \\
\hline Mean & 1.93 & 2.07 & 2.33 & 2.77 & 3.21 \\
\hline (Range) & $(1.39-3.01)$ & $(1.30-3.07)$ & $(1.40-4.59)$ & $(1.62-5.94)$ & $(1.71-8.06)$ \\
\hline Between practice CV (\%) & 23.0 & 24.7 & 34.2 & 42.1 & 45.1 \\
\hline$p$-value (t-test) & 0.0002 & & & & \\
\hline$p$-value (Bonett-Seier test) & $0.00031^{*}$ & & & & \\
\hline \multicolumn{6}{|l|}{ Urban } \\
\hline Mean & 1.80 & 2.03 & 2.31 & 2.47 & 2.86 \\
\hline (Range) & $(798-2543)$ & $(809-2356)$ & $(879-2205)$ & $(893-2297)$ & $(942-2368)$ \\
\hline Between practice CV (\%) & 24.4 & 27.6 & 33.0 & 25.5 & 25.3 \\
\hline$p$-value (t-test) & $<0.0000001^{*}$ & & & & \\
\hline$p$-value (Bonett-Seier test) & $0.008^{*}$ & & & & \\
\hline
\end{tabular}


Table 3. Standardised test request rates pre- and post-intervention for PSA (expressed as number of tests per 1000 male patients). Asterisk: Statistically significant difference $(p<0.05)$ between the pre- and post-intervention data.

\begin{tabular}{|c|c|c|c|c|c|}
\hline & $\begin{array}{c}\text { Pre- } \\
\text { intervention }\end{array}$ & & Intervention & & $\begin{array}{c}\text { Post- } \\
\text { intervention }\end{array}$ \\
\hline Year & 2011-2012 & $2012-2013$ & 2013-2014 & $2014-2015$ & $2015-2016$ \\
\hline \multicolumn{6}{|l|}{ All } \\
\hline Mean & 69.4 & 79.2 & 79.6 & 74.8 & 82.9 \\
\hline (Range) & $(19.6-279.3)$ & $(19.9-396.1)$ & $(23.1-527.6)$ & $(17.1-274.0)$ & $(26.4-296.9)$ \\
\hline Between practice $\mathrm{CV}$ & 67.5 & 78.9 & 90.2 & 62.7 & 65.7 \\
\hline$p$-value (t-test) & $0.006^{*}$ & & & & \\
\hline$p$-value (Bonett-Seier test) & 0.60 & & & & \\
\hline \multicolumn{6}{|l|}{ Rural } \\
\hline Mean & 87.4 & 101.9 & 103.1 & 93.4 & 106.8 \\
\hline (Range) & $(29.7-279.3)$ & $(35.5-396.1)$ & $(27.8-527.6)$ & $(38.5-274.0)$ & $(35.7-296.9)$ \\
\hline Between practice $\mathrm{CV}$ & 66.6 & 80.0 & 97.4 & 64.1 & 65.2 \\
\hline$p$-value (t-test) & 0.08 & & & & \\
\hline$p$-value (Bonett-Seier test) & 0.72 & & & & \\
\hline \multicolumn{6}{|l|}{ Urban } \\
\hline Mean & 55.4 & 61.6 & 61.4 & 60.3 & 64.4 \\
\hline (Range) & $(19.6-134.6)$ & $(19.9-170.9)$ & $(23.1-125.8)$ & $(17.1-129.8)$ & $(26.4-132.8)$ \\
\hline $\mathrm{CV}$ & 53.9 & 56.1 & 45.2 & 44.0 & 43.9 \\
\hline$p$-value (t-test) & $0.002^{*}$ & & & & \\
\hline$p$-value (Bonett-Seier test) & 0.98 & & & & \\
\hline
\end{tabular}

